\title{
SUNCT Headache
}

National Institute of Neurological Disorders and Stroke (NINDS)

\section{Source}

National Institute of Neurological Disorders and Stroke (NINDS). SUNCT Headache

Information Page.

SUNCT-Short-lasting, Unilateral, Neuralgiform headache attacks with Conjunctival injection and Tearing-is a rare form of headache that is most common in men after age 50. The disorder is marked by bursts of moderate to severe burning, piercing, or throbbing pain, usually on one side of the head and around the eye or temple. The pain usually peaks within seconds of onset and may follow a pattern of increasing and decreasing intensity. Attacks typically occur in daytime hours and last from 5 seconds to 4 minutes per episode. Individuals generally have five to six attacks per hour.

Autonomic nervous system responses include watery eyes, reddish or bloodshot eyes caused by dilation of blood vessels (conjunctival injection), nasal congestion, runny nose, sweaty forehead, swelling of the eyelids, and increased pressure within the eye on the affected side of head. Systolic blood pressure may rise during the attacks. Movement of the neck may trigger these headaches. SUNCT may be a form of trigeminal neuralgia and is considered one of the trigeminal autonomic cephalgias, or TACs. 